\title{
Application of ATR-FTIR Spectroscopy to Compare the Cell Materials of Wood Decay Fungi with Wood Mould Fungi
}

\author{
Barun Shankar Gupta, ${ }^{1}$ Bjørn Petter Jelle, ${ }^{1,2}$ and Tao Gao ${ }^{1}$ \\ ${ }^{1}$ Department of Civil and Transport Engineering, Norwegian University of Science and Technology (NTNU), Høgskoleringen 7A, \\ 7491 Trondheim, Norway \\ ${ }^{2}$ Department of Materials and Structures, SINTEF Building and Infrastructure, Høgskoleringen 7B, 7465 Trondheim, Norway
}

Correspondence should be addressed to Barun Shankar Gupta; bsbarun@gmail.com

Received 10 June 2015; Revised 22 July 2015; Accepted 26 July 2015

Academic Editor: Feride Severcan

Copyright (C) 2015 Barun Shankar Gupta et al. This is an open access article distributed under the Creative Commons Attribution License, which permits unrestricted use, distribution, and reproduction in any medium, provided the original work is properly cited.

Wood fungi create vast damage among standing trees and all types of wood materials. The objectives of this study are to (a) characterize the cell materials of two major wood decay fungi (Basidiomycota), namely, Trametes versicolor and Postia placenta, and (b) compare the cell materials of decay fungi with four wood mould fungi (Ascomycota), namely, Aureobasidium pullulans, Alternaria alternata, Cladosporium cladosporioides, and Ulocladium atrum. Fourier transform infrared (FTIR) spectroscopy is used to characterize the microbial cellular materials. The results showed that the IR bands for the fatty acid at $\sim 2900 \mathrm{~cm}^{-1}$ were different for the two-decay-fungi genre. Postia placenta shows more absorbance peaks at the fatty acid region. Band ratio indices for amide I and amide II from protein amino acids were higher for the mould fungi (Ascomycota) than the decay fungi (Basidiomycota). Similarly, the band ratio index calculated for the protein end methyl group was found to be higher for the mould fungi than the decay fungi. Mould fungi along with the decay fungi demonstrated a positive correlation $\left(R^{2}=0.75\right)$ between amide I and amide II indices. The three-component multivariate, principal component analysis showed a strong correlation of amide and protein band indices.

\section{Introduction}

Wood fungi are broadly classified into two major categories, namely, decay fungi and mould fungi $[1,2]$. Decay or deterioration is performed predominantly by brown rot and white rot fungi, while staining or discolouration of wood is performed by mould fungi $[3,4]$. Decay and staining reduce the performance of wood material either structurally or aesthetically. Cell structure of fungi has been widely studied for taxonomy and physiology by using various methods other than spectroscopy [5-13]. The fatty acids that are produced in a fungal cell are species specific [14]. Fungal identification libraries of Phanerochaete chrysosporium, $P$. sordida, $P$. sanguinea, Trametes versicolor, $T$. hirsuta, and $T$. pubescens have been made by extraction and esterification of fungal cellular fatty acids that were characterized by gas chromatography [14]. However, analyzing the chromatographic result, the investigators observed wide variability in the maximum and minimum values. The variation in the amount of deoxyribonucleic acid (DNA) among fungi is often used to characterize species and strains. Attenuated total reflectance (ATR) Fourier transform infrared (FTIR) spectroscopy is a fast surface characterizing tool that can provide chemical information about a substrate up to several micrometres deep. Fungal characterization by FTIR spectroscopy, though not new, is, therefore, an exciting and challenging task as vast information is made available from the microbial structure without the extraction of cell materials [6, 15-17]. The questions that originate from spectroscopic studies are as follows. (i) How to represent the spectroscopic findings? (ii) What information should be used for spectral analysis? (iii) How reliable are the spectroscopic data?

In this study, two naturally abundant wood rot fungi, Trametes versicolor and Postia placenta, and four common wood mould fungi, Aureobasidium pullulans, Alternaria alternata, Cladosporium cladosporioides, and Ulocladium 


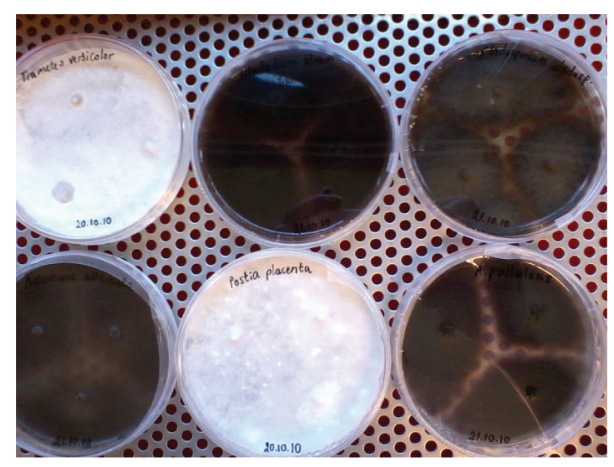

FIGURE 1: Cultivation of decay and mould fungi on agar.

atrum, were cultivated. The objectives of this study are to evaluate the applicability of ATR-FTIR spectroscopy to

(1) identify cell materials of rot fungi (Basidiomycota);

(2) identify cell materials of mould fungi (Ascomycota);

(3) quantify spectral information of two rot fungi and four mould fungi.

\section{Materials and Methods}

2.1. Fungi Culture. The white rot fungus, Trametes versicolor (strain CTB 863A), was cultivated on agar plates containing $20 \mathrm{~g}$ Fluka malt, $10 \mathrm{~g}$ Fluka agar (4\%), and $500 \mathrm{~mL}$ water. The brown rot fungus, Postia placenta (strain FPRL 280), was cultivated on agar plates containing $20 \mathrm{~g}$ Bacto malt, $10 \mathrm{~g}$ NMD agar (4\%, NMD = Norsk Medisinaldepot AS), and $500 \mathrm{~mL}$ water. The wood mould fungi, Aureobasidium pullulans (strain DSM 2404), Alternaria alternata (strain DSM 62010), Cladosporium cladosporioides (strain DSM 62121), and Ulocladium atrum (strain DSM 63068), were cultivated separately in agar mediums containing $0.5 \mathrm{~L}$ of ionized water, $6.25 \mathrm{~g}$ Bacto malt, and $10 \mathrm{~g}$ NMD agar $(\mathrm{NMD}=$ Norsk Medisinaldepot AS). The mould fungi strains were procured from the Deutsche Sammlung von Mikroorganismen und Zellkulturen GmbH (DSMZ, Germany). Fungi culture was performed at the Norwegian Forest and Landscape Institute, Ås, Norway.

\subsection{Fungi Characterization. Thermo Electron Nicolet 8700} FTIR spectrometer, fitted with a Smart Orbit attenuated total reflectance (ATR) accessory, was used to obtain infrared spectra. Mycelia of each fungal strain from agar plates (Figure 1) were carefully picked by clean tweezers. Specimens were then placed on top of the diamond crystal of the ATRFTIR spectroscopy accessory. Mechanical pressure from a rotating knob was applied to the specimens to acquire adequate contact with the diamond crystal. Vibrational spectra were collected at ambient conditions at room temperature and room humidity. Further spectral corrections were not performed. A minimum of three replicates of spectra were obtained from three specimens selected arbitrarily from the agar plates for each fungal species. The mid-IR region of $4000-400 \mathrm{~cm}^{-1}$ was evaluated to characterize the cell materials. Averages of 32 scans were obtained for a single spectrum.
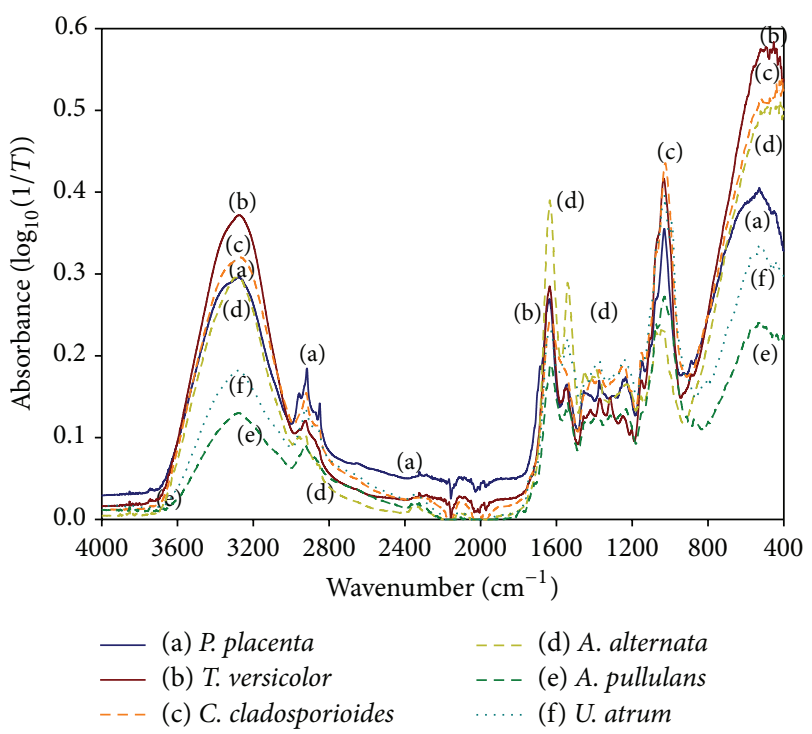

FIGURE 2: FTIR spectra of two wood decay fungi ((a) and (b)) and four wood mould fungi ((c), (d), (e), and (f)).

OMNIC software was used for spectral analysis. Spectra with noise-free, sharp, and prominent peaks were selected to interpret the chemical structures, where absorbance $\left(A^{\prime}\right)$ of a pure specimen is governed by Beer-Lambert law as $A^{\prime}=\log _{10}(1 / T)$, with $T$ being the transmittance. Sigma Plot software (V. 11, Systat Software, Inc.) was used for plotting of graphs and for performing regression analysis. Scanning electron microscopic (SEM) back scatter electron (BSE) images, $15 \mathrm{kV}$, were obtained on a carbon black tape background.

2.3. Statistical Analysis. Pearson's correlation coefficient ( $r$ ) was used to measure the strength of association between two variables. Coefficients of determination $\left(R^{2}\right.$ ordinary and $R^{2}$ adjusted for coefficients) were used to indicate the amount of variation in the response variable explained by the independent variable for the linear regression model. Larger $R^{2}$ indicates more variability which is explained by the linear model. Chi-square distribution was used to ascertain the goodness of fit. Multivariate principal component analysis (PCA) was used to simplify the problem of variable groups by replacing a group of variables with a single new variable. Each principal component represents a linear combination of the original variables. The variance of this variable is the maximum among all possible choices of the axis. MINITAB software version 16.2.1 was used for statistical analysis. Three replicates from specimens of each fungal species were used for FTIR spectra representation and four replicates for each fungal species were used for regression analysis.

\section{Results and Discussion}

While fungi culture was performed for decay/rot fungi, the spectral findings of mould fungi were imported from a previous research work [18]. Several common IR bands were initially recognized in the FTIR vibrational spectra. Figures 2, 3, and 4 illustrate the FTIR absorbance spectra 

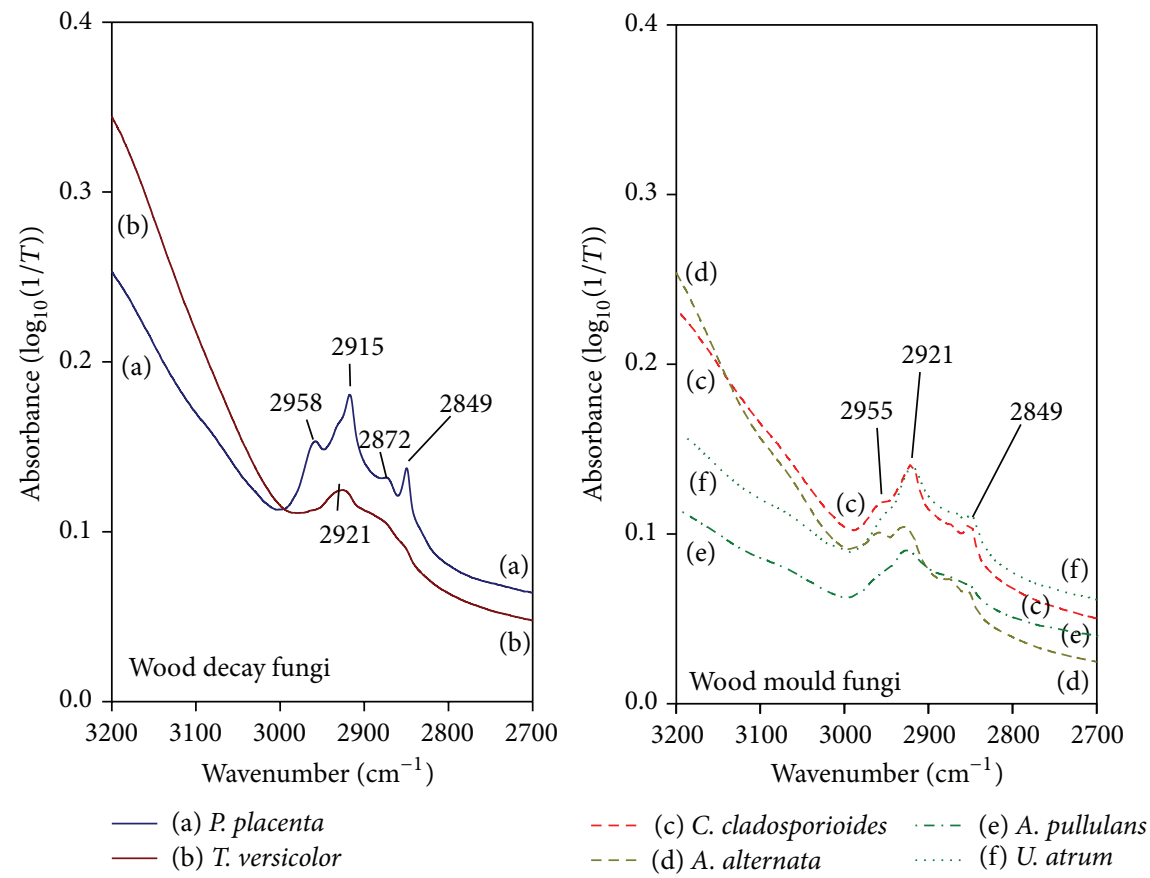

FIGURE 3: FTIR absorbance spectra of two wood decay fungi ((a) and (b)) and four wood mould fungi ((c), (d), (e), and (f)) showing the fatty acid region.

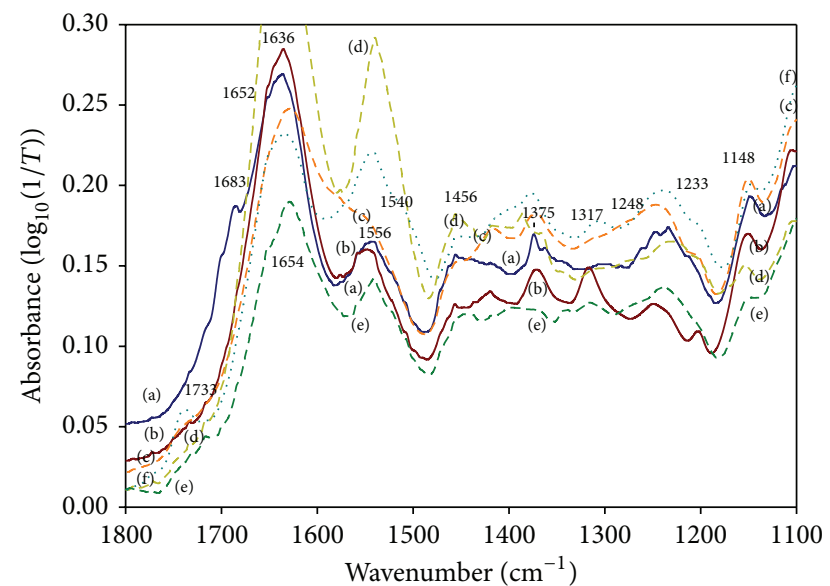
(a) P. placenta
(b) T. versicolor
- - (c) C. cladosporioides
(d) A. alternata
(e) A. pullulans
(f) U. atrum

FIGURE 4: FTIR absorbance spectra of two wood decay fungi ((a) and (b)) and four wood mould fungi ((c), (d), (e), and (f)) showing fingerprint regions.

of the two wood rot fungi (Trametes versicolor and Postia placenta) and the four wood mould fungi (Aureobasidium pullulans, Alternaria alternata, Cladosporium cladosporioides, and Ulocladium atrum). The broad peak around $\sim 3400 \mathrm{~cm}^{-1}$ represents the presence of stretching vibrations of hydrogenbonded $\mathrm{O}-\mathrm{H}\left(v_{\text {str }}\right)$ that comes from $\mathrm{H}_{2} \mathrm{O}$ or bonded $\mathrm{N}-\mathrm{H}$. The amount of hydroxyl radical from the nutrient substrate contributes significantly to the degradation mechanism by rot fungi $[19,20]$. Fatty acids show characteristic absorbance at the $2950-2845 \mathrm{~cm}^{-1}$ wavenumber region. The absence of high intensity peaks of fatty acids for Trametes versicolor at the fatty acid region is notable. Absorbances by amide and polysaccharide moieties were observed at wavenumbers $1650-1050 \mathrm{~cm}^{-1}$. Amides show two absorption bands, amide I and amide II, at $\sim 1700-1500 \mathrm{~cm}^{-1}$ due to vibrational coupling between stretching frequencies of $\mathrm{C}=\mathrm{O} v_{\text {str }}$ and $\mathrm{N}$ $\mathrm{H}$ deformation. Amide I has high $\mathrm{C}=\mathrm{O} v_{\text {str }}$ character from $\beta$-sheet of protein, while amide II has lesser $\mathrm{C}=\mathrm{O}$ character and demonstrates interactions between $\mathrm{C}=\mathrm{O} \nu_{\text {str }}$ and $\mathrm{N}-\mathrm{H}$ deformation coupling. Phospholipids and $\mathrm{PO}_{2}$ show bands at $1237 \mathrm{~cm}^{-1}$ and $1082 \mathrm{~cm}^{-1}$ for asymmetric stretching and symmetric stretching vibrations, respectively [21]. Figure 3 for the two wood decay fungi and the four wood mould fungi shows the presence of aliphatic $\mathrm{C}-\mathrm{H} \nu_{\text {str }}$ from esters or triglycerides at $2958 \mathrm{~cm}^{-1}$, from fatty acids, phospholipids, glycerol, and triglycerides at $2921 \mathrm{~cm}^{-1}, 2915 \mathrm{~cm}^{-1}$, and $2849 \mathrm{~cm}^{-1}$, and from shoulders at $2872 \mathrm{~cm}^{-1}$ and $2852 \mathrm{~cm}^{-1}$, respectively.

3.1. Mould Fungi. Figure 4 shows that, at lower wavenumbers, mould fungi cell lipids show band at $1456 \mathrm{~cm}^{-1}$ for $\mathrm{CH}_{2}$ bending mode and band at $1402 \mathrm{~cm}^{-1}$ for $\mathrm{C}=\mathrm{O}$ symmetric stretching of $\mathrm{COO}$ groups as observed in previous research [18]. In general, aromatic and alkene $\mathrm{C}-\mathrm{H} \nu_{\text {str }}$ bands appear slightly above $\sim 3000 \mathrm{~cm}^{-1}$, while alkane C-H $v_{\text {str }}$ appears below $\sim 3000 \mathrm{~cm}^{-1}$. Glucans, chitins, amines, and acids are common fungal cell wall components [14, 22-27].

The cell carbohydrates of the four wood mould fungi (Aureobasidium pullulans, Alternaria alternata, Cladosporium cladosporioides, and Ulocladium atrum) show bands 
due to vibration modes at $1064 \mathrm{~cm}^{-1}$ for $\mathrm{CH}_{2} \mathrm{OH}$ and $\mathrm{C}-\mathrm{O}$ stretching vibration coupled with the $\mathrm{C}-\mathrm{O}$ bending mode, $1773 \mathrm{~cm}^{-1}$ for $\mathrm{C}=\mathrm{O}$ carboxyl stretching vibration, $1713-1711 \mathrm{~cm}^{-1}$ for carboxyl $\mathrm{C}=\mathrm{O}, 1662-1659 \mathrm{~cm}^{-1}$ for amide $\mathrm{C}=\mathrm{O}$ [28], $1592 \mathrm{~cm}^{-1}$ and $1615 \mathrm{~cm}^{-1}$ for asymmetric $\mathrm{COO}^{-}$, $1546 \mathrm{~cm}^{-1}$ and $1552 \mathrm{~cm}^{-1}$ for $\mathrm{NH}$ bending deformation, $1502 \mathrm{~cm}^{-1}$ and $1516 \mathrm{~cm}^{-1}$ for $\mathrm{C}=\mathrm{C}$ aromatic, $1454 \mathrm{~cm}^{-1}$ and $1466 \mathrm{~cm}^{-1}$ for $\mathrm{CH}_{2}$ bending deformation of lipid and polysaccharide, $883-892 \mathrm{~cm}^{-1}$ for $\beta$-chitin and $\gamma$-CHx vibration at $962 \mathrm{~cm}^{-1}$ for $\alpha$-chitin, and $750-700 \mathrm{~cm}^{-1}$ for C-H out-ofplane bending vibration [18]. Alternaria alternata and Aureobasidium pullulans show two distinct peaks at $1733 \mathrm{~cm}^{-1}$ and $1717 \mathrm{~cm}^{-1}$, while Ulocladium atrum shows a broad peak at higher wavenumber of $1740-1733 \mathrm{~cm}^{-1}$ [18].

3.2. Decay Fungi. Absorbance at $\sim 2200-1900 \mathrm{~cm}^{-1}$ is overshadowed by the interference from the diamond crystal absorption and spectral noise. Subsequently, there is no possibility to identify the presence of cumulative double bonds, antisymmetric $\mathrm{C}=\mathrm{C} v_{\text {str }}$, at $2000 \mathrm{~cm}^{-1}$ (Figure 4). However, there is a sharp peak at $2323 \mathrm{~cm}^{-1}$ for both decay and mould fungi that could possibly have originated from ketenes, $\mathrm{O}=\mathrm{C}=\mathrm{O}$. The absence of any strong band at $\sim 2250 \mathrm{~cm}^{-1}$ eliminates the probability of presence of nitrile group, characterized by $\mathrm{C} \equiv \mathrm{N} v_{\text {str }}$ absorption. Trametes versicolor shows higher intensities at the $\sim 3400 \mathrm{~cm}^{-1}$ region. Bonded amines, $\mathrm{N}-\mathrm{H} v_{\text {str }}$, display characteristic absorption at $\sim 3300 \mathrm{~cm}^{-1}$ region and $\equiv \mathrm{C}-\mathrm{H} \nu_{\text {str }}$ shows characteristic absorption band at $\sim 3320 \mathrm{~cm}^{-1}$. The band at $\sim 2850 \mathrm{~cm}^{-1}$ is the characteristic absorption band for symmetric stretching of $\mathrm{CH}_{2}$. C-H $v_{\text {str }}$ absorbance peaks are more prominent for Postia placenta compared to Trametes versicolor. The replicates of spectra from Trametes versicolor yield broad bands at $2921 \mathrm{~cm}^{-1}$ and $2852 \mathrm{~cm}^{-1}$. The replicates of spectra from Postia placenta have strong absorption bands at $2958 \mathrm{~cm}^{-1}, 2915 \mathrm{~cm}^{-1}, 2872 \mathrm{~cm}^{-1}$, and $2849 \mathrm{~cm}^{-1}$. The absence of the band at $2872 \mathrm{~cm}^{-1}$ in the spectra of Trametes versicolor indicates that possibly Postia placenta has higher numbers of alkyl and alkane chain numbers in fatty acid configuration.

The fingerprint region for the wood rot decay fungi, Trametes versicolor and Postia placenta, is shown in Figure 4. The spectra for both fungi are largely similar in pattern except some more peaks for Postia placenta. Small shoulder at $1733 \mathrm{~cm}^{-1}$ of the spectrum originated from Trametes versicolor shows the presence of $\mathrm{C}=\mathrm{O} v_{\text {str }}$ band for uronic acids or from saturated esters. The overtone of $\mathrm{C}=\mathrm{O} v_{\text {str }}$ band is not distinguishable at $3400 \mathrm{~cm}^{-1}$. A peak at $1717 \mathrm{~cm}^{-1}$ from both of the fungi and a small shoulder at $1700 \mathrm{~cm}^{-1}$ from Postia placenta suggest possible presence of carbonyl group in conjunction with a double bond or Glu $(\mathrm{C}=\mathrm{O})$ or $\mathrm{Asp}$ $(\mathrm{C}=\mathrm{O})$ amino acids [29]. The possibility of presence of the $\mathrm{C}=\mathrm{O}$ group is further supported by a strong peak in the Postia placenta spectrum at $1683 \mathrm{~cm}^{-1}$ which could have resulted due to chelation between $\mathrm{C}=\mathrm{O}$ group and a neighbouring $\mathrm{O}-\mathrm{H}$ group. The presence of $\mathrm{O}-\mathrm{H}$ along with $\mathrm{C}=\mathrm{O} v_{\text {str }}$ is also evidenced by $\mathrm{O}-\mathrm{H}$ deformation at $932 \mathrm{~cm}^{-1}$ found in the spectrum of both decay and mould fungi. Henceforth, these bands have originated from carboxyl groups present in the cell structures of the fungi. Two shoulders at $1654 \mathrm{~cm}^{-1}$ and $1652 \mathrm{~cm}^{-1}$ are probable peaks from characteristic absorptions of zwitterions $-\mathrm{N}^{+}-\mathrm{H} \nu_{\text {str }}$ and $-\mathrm{CO}_{2}{ }^{-} \nu_{\text {str }}$ from asymmetric stretching of amino acids, $\operatorname{Arg}\left(\mathrm{CN}_{3} \mathrm{H}_{5}^{+}\right)$, and acetamides from chitin [28]. A strong absorption at $\sim 1556 \mathrm{~cm}^{-1}$ is due to amide II from $\alpha$-helix of protein, Glu $\left(\mathrm{COO}^{-}\right)$, and/or chitin. The band at $1505 \mathrm{~cm}^{-1}$ shows the presence of $\mathrm{o}-/ \mathrm{m}$ substituted aromatic units, indole groups of amino acids $(\mathrm{CN}, \mathrm{CH}$, and $\mathrm{NH})$, that is, Trp amino acid. The band at $1496 \mathrm{~cm}^{-1}$ is assigned to aromatic (CC) ring, Tyr $\left(\mathrm{O}^{-}, \mathrm{CC}\right.$, $\mathrm{CH})$, or $\operatorname{Trp}(\mathrm{CC}, \mathrm{CH})$ amino acid [29]. The small band at $1456 \mathrm{~cm}^{-1}$ for asymmetric $\mathrm{CH}_{3}$ bending modes of end ethyl groups of protein and $1419 \mathrm{~cm}^{-1}$ could be due to absorption from carboxymethyl $\mathrm{COO}^{-}$units [29]. A strong band at $1375 \mathrm{~cm}^{-1}$ is due to chitin. The strong band at $1317 \mathrm{~cm}^{-1}$ can be assigned to amide III from proteins and chitins, $1248 \mathrm{~cm}^{-1}$ for stretching of non-hydrogen-bonded $\mathrm{PO}_{2}$ group of phosphodiester groups of nucleic acid, $1202 \mathrm{~cm}^{-1}$ for $\mathrm{P}=\mathrm{O}$ stretch, and $1148 \mathrm{~cm}^{-1}$ for $\alpha$-Glucans. Bands at $1146 \mathrm{~cm}^{-1}$ are due to COC/CC from $\alpha$-Glucan complexes, a shoulder at $1075 \mathrm{~cm}^{-1}$ is due to CO/CC from $\beta$-Glucan complexes, the band at $1023 \mathrm{~cm}^{-1}$ is for $\alpha$-Glucan complexes or cellulose$\mathrm{OH}$, the band at $930 \mathrm{~cm}^{-1}$ is for aromatic rings, and finally the bands at $888 \mathrm{~cm}^{-1}$ and $848 \mathrm{~cm}^{-1}$ represent C-1-H of $\beta$-Glucan and $\mathrm{C}-1-\mathrm{H}$ of $\alpha$-Glucan units, respectively. Absorbance below $800 \mathrm{~cm}^{-1}$ could be due to the overtones of bands at higher frequencies.

There is an additional peak at $1683 \mathrm{~cm}^{-1}$ for Postia placenta. The observed differences between Trametes versicolor and Postia placenta in Figures 3 and 4 have resulted due to the presence and/or absence of different proportions of hydrocarbons and fatty acids. Presence of the acid groups would have resulted in sharp peaks, while absence would have resulted in no absorbance. Extracellular $\mathrm{OH}$ groups are present in Trametes versicolor [30]. Moreover, it is known that Postia placenta secretes oxalic acid into the sheath environment $[19,31]$. Hence, the sharp peak at $1683 \mathrm{~cm}^{-1}$ in Figure 4 is probably due to the IR detection of carbonyl groups.

Overall, as observed by previous researchers $[6,32]$, it can be concluded that there is strong evidence of presence of chitin, Glucans, and glycoproteins that are covalently linked together in a dynamic process that could occur extracellularly or intercellularly. The probing depth of ATR-FTIR spectroscope was enough to sense bond-vibration signal of these active groups.

3.3. Quantitative Spectral Analysis for Six Fungal Species. Based on the observations in Figures 2, 3, and 4, the ATR-FTIR band ratio indices at $1650 \mathrm{~cm}^{-1}, 1546 \mathrm{~cm}^{-1}$, and $1456 \mathrm{~cm}^{-1}$ wavenumbers in the IR spectral region for the six fungal genre were calculated [18] in the following way:

$$
\text { Band ratio index }=\frac{I_{a}}{I_{2921}},
$$

where $I_{a}$ is the band intensity at the observed wavenumber " $a$ " $\mathrm{cm}^{-1}$ and $I_{2921}$ is the band intensity at wavenumber 


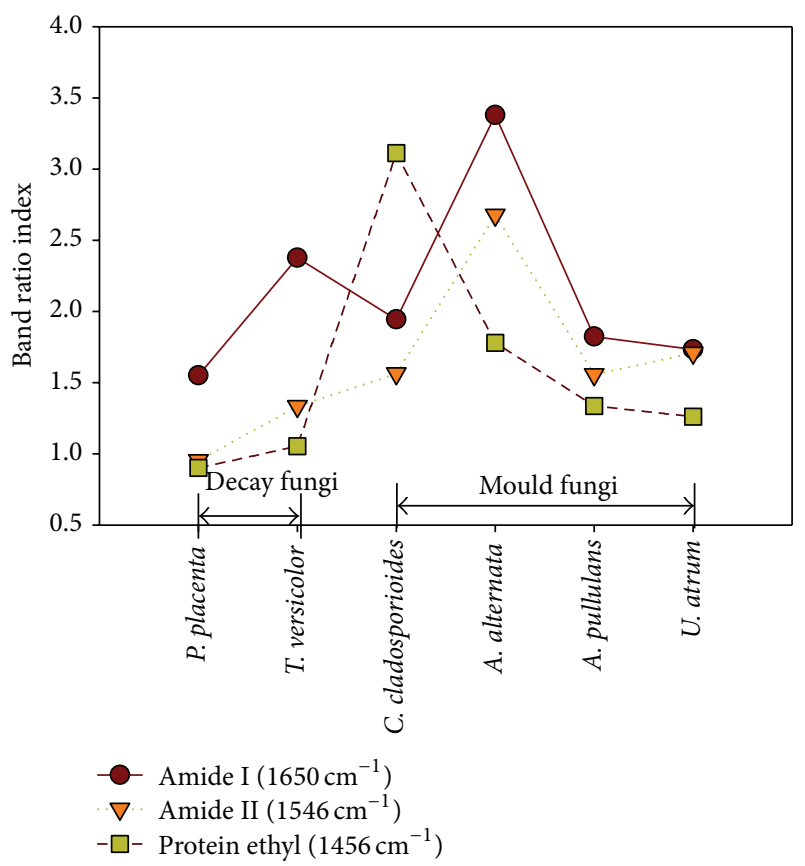

FIGURE 5: The band ratio indices (from (1)) of two wood decay fungi and four wood mould fungi.

$2921 \mathrm{~cm}^{-1}$. The band ratio index calculated at $1456 \mathrm{~cm}^{-1}$ and at $1650 \mathrm{~cm}^{-1}$ for the decay fungi and the mould fungi is not linear as is observed in Figure 5. Observing the pattern for the fungi belonging to Ascomycota and Basidiomycota, it may be concluded that the amide I and amide II indices do not overlap. Figure 5 demonstrates that the band ratio index for the protein ethyl group $\left(1456 \mathrm{~cm}^{-1}\right)$ and the amide II index $\left(1546 \mathrm{~cm}^{-1}\right)$ are higher for the four genera of wood mould fungi. The amide I index of one wood decay fungus (T. versicolor) is larger than the amide I index of three wood mould fungi, indicating that rot fungi have higher presence of amide I group over the lipids in the cellular structure. Additionally, the results from Figure 5 indicate that the increase in intensities of protein amide bands, amide I and amide II, will not be accompanied by an increase in intensity of the protein end ethyl group, since there is no significant visible relationship. Pearson's correlation coefficient, " $r$," measuring the degree of linear relationship between two variables obtained from statistical multivariate item analysis yields 0.806 (for indices at $1650 \mathrm{~cm}^{-1}$ and $1546 \mathrm{~cm}^{-1}$ ), 0.158 (for $1650 \mathrm{~cm}^{-1}$ and $1456 \mathrm{~cm}^{-1}$ ), and 0.307 (for $1546 \mathrm{~cm}^{-1}$ and $\left.1456 \mathrm{~cm}^{-1}\right)$. Therefore, from the correlation coefficient " $r$," it may be concluded that the IR band index pairs at higher wavenumbers (for $1650 \mathrm{~cm}^{-1}$ and $1546 \mathrm{~cm}^{-1}$ ) follow a high degree of linear trend, either increasing or decreasing, compared to the IR band index at the lower wavenumbers.

Larger values of the band ratio indices are obtained for mould fungi and lower values are obtained for decay fungi from Figure 5. The investigated set of fungi shows presence of higher amount of protein materials for the mould fungi that may have resulted due to higher amount of nucleic acids. The other reason could be the fact that the mould fungi invade wood before the decay fungi attack sets in. Thus, the mould fungi had access to higher nitrogen rich nutrient sources and consequently their metabolic system shows higher presence of nitrogenous material.

In the linear regression model with 24 units of data from cumulative observations of all four replicates for the six fungi, it was observed that the statistical coefficient of determination, $R^{2}=0.75$, for amide I accounts for $75 \%$ (adjusted $R^{2}=0.69$ ) of the total variations in amide II. Henceforth, as seen in Figure 5, it may be concluded that the cell material of decay fungi is not similar to wood mould fungi resulting in $R^{2}<1.00$. Previous research on bacterial cell component has reported similar positive correlation with the normalised intensities of amide II/C-H bands and the $\mathrm{N} / \mathrm{C}$ elemental surface concentration ratio of the strains determined by X-ray photoelectron spectroscopy (XPS) [33]. The authors conferred that there is higher nitrogen content on the bacteria as compared to yeasts. Additionally, quantification of the peak areas at $1510 \mathrm{~cm}^{-1}, 1138 \mathrm{~cm}^{-1}$, and $1758 \mathrm{~cm}^{-1}$ to follow degradation changes in wood substrate by ATR-FTIR spectroscopy showed increasing amount in lignin/carbohydrate ratio with degradation period [34-36].

Table 1 shows the descriptive statistics for each variable considered in Figure 5. Assuming normal distribution, Chisquare test was performed with hypothesized standard deviation $=0.5$. From the $p$ value [probability $(X>$ test statistic $)$ ] in Table 1, it can be concluded with $95 \%$ confidence limit that the band index calculated at $I_{1456} / I_{2921}$ does not follow a multinomial distribution with specific proportion.

An IR spectrum contains more information than is needed. The entire spectrum is used to obtain absorbance values of a few peaks of interest. However, by using peak indices as variables $\left(I_{1650} / I_{2921}, I_{1546} / I_{2921}\right.$, and $\left.I_{1456} / I_{2921}\right)$ in principal component analysis (PCA) technique, redundant data that are not useful can be reduced. A principal component analysis (PCA), assuming normal distribution, shows (Table 1) that the band index calculated at $I_{1546} / I_{2921}$ has the largest percentage of the total data variation, followed by index at $I_{1456} / I_{2921}$ and $I_{1650} / I_{2921}$. The larger correlations are in bold fonts in Table 1. The first principal component of a variable has the largest sample variance amongst all normalized linear combinations of the columns. Subsequent principal components have maximum variance subject to being orthogonal to the earlier ones. The first principal component (PC1) correlates most strongly with $I_{1456} / I_{2921}$. Moreover, all the 3 variables show correlation with a value above 0.5 , suggesting that these three band indices vary together to certain extent for the first component. The second principal component (PC2) correlates strongly with $I_{1456} / I_{2921}$ and has negative correlation with $I_{1650} / I_{2921}$. PC2 can be viewed as the measure of $I_{1456} / I_{2921}$ and lack of $I_{1650} / I_{2921}$. The third principal component (PC3) has the strongest negative correlation with $I_{1546} / I_{2921}$ and positive correlation with $I_{1650} / I_{2921}$. Henceforth, PC3 can be viewed as the measure of $I_{1650} / I_{2921}$ with lack of $I_{1546} / I_{2921}$. Therefore, a regression model in future with IR band ratio index would exclude the component that has the largest variation. 
TABLE 1: Summary of the Chi-square test and principal component analysis (strong interactions are in bold letters).

\begin{tabular}{lccccccc}
\hline \multirow{2}{*}{ Variable $(n=6)$} & \multirow{2}{*}{ Standard deviation } & \multicolumn{3}{c}{ Chi-square } & \multicolumn{3}{c}{ Principal component analysis } \\
& & 95\% confidence interval & Test statistic & $p$ value & PC1 & PC2 & PC3 \\
\hline$I_{1650} / I_{2921}$ & 0.670 & $(0.418,1.643)$ & 8.98 & 0.220 & 0.563 & -0.546 & $\mathbf{0 . 6 2 1}$ \\
$I_{1546} / I_{2921}$ & 0.576 & $(0.359,1.412)$ & 6.63 & 0.500 & 0.528 & -0.341 & $-\mathbf{0 . 7 7 8}$ \\
$I_{1456} / I_{2921}$ & 0.811 & $(0.506,1.989)$ & 13.15 & 0.044 & $\mathbf{0 . 6 3 6}$ & $\mathbf{0 . 7 6 5}$ & 0.096 \\
\hline
\end{tabular}

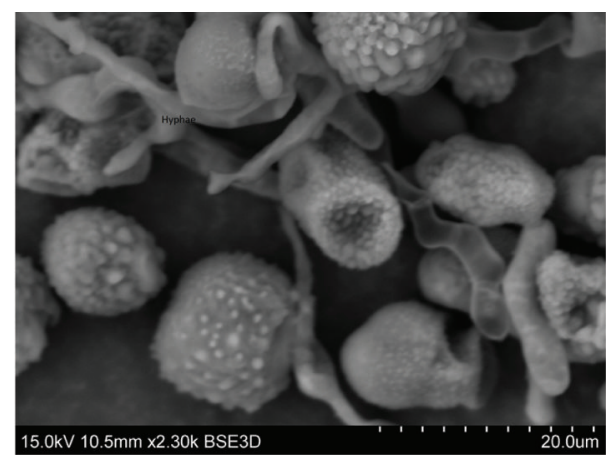

FIGURE 6: SEM image of fungal spores and hypha.

Figure 6 shows the scanning electron microscopic image of Basidiomycota fungal spores on a carbon black tape background. Researches have shown that there could be crystal depositions on the hypha depending on the wood substrate [19]. The small dimensions of the spores and hyphae from Figure 6 suggest that the ATR-FTIR signal from a single beam spot on fungal surface could not be singly due to the hypha; however, it could be from both the hyphae and amino acid rich spores.

\section{Conclusions}

Fourier transform infrared (FTIR) spectroscopy is used to compare cellular materials of wood decay and wood mould fungi. Infrared (IR) bands originating from six fungal species showed marked differences. Specifically, it was observed that

(1) chitin and fatty acid were present in all six fungi;

(2) spectra from Trametes versicolor (Basidiomycota) yield broad bands at $2921 \mathrm{~cm}^{-1}$ and $2852 \mathrm{~cm}^{-1}$. Contrarily, the spectra from Postia placenta (Basidiomycota) have strong absorption bands at $2958 \mathrm{~cm}^{-1}$, $2915 \mathrm{~cm}^{-1}, 2872 \mathrm{~cm}^{-1}$, and $2849 \mathrm{~cm}^{-1}$;

(3) Ascomycota and Basidiomycota amide I and amide II indices (for indices at $1650 \mathrm{~cm}^{-1}$ and $1546 \mathrm{~cm}^{-1}$ ) do not overlap. The calculated amide II index at $1546 \mathrm{~cm}^{-1}$ is less for the two decay (Basidiomycota) fungi than for the four mould (Ascomycota) fungi;

(4) multivariate analysis provides Pearson's correlation coefficient, $r=0.8$, for amide I and amide II (for indices at $1650 \mathrm{~cm}^{-1}$ and $1546 \mathrm{~cm}^{-1}$ ) indicating a positive linear correlation;
(5) additionally, $75 \%$ of the variation could be explained in the linear relationship between band indices of amide I at $1650 \mathrm{~cm}^{-1}$ and amide II at $1546 \mathrm{~cm}^{-1}\left(R^{2}=\right.$ $0.75)$;

(6) the protein ethyl index at $1456 \mathrm{~cm}^{-1}$ shows a decreasing trend for the four mould fungi Cladosporium cladosporioides $>$ Alternaria alternata $>$ Aureobasidium pullulans > Ulocladium atrum;

(7) principal component analysis was found to be useful to define the nature of correlation between the bands indices calculated from fingerprint regions. It was observed that the band index calculated at $I_{1546} / I_{2921}$ has the largest percentage of the total data variation.

In conclusion, this study shows that ATR-FTIR spectroscopy provides information about fungal cellular structure that is specific to genus and species. Inter- and intraspecies comparison by FTIR spectroscopy shows the potential to generate future databanks to identify various fungi and pathogens.

\section{Conflict of Interests}

The authors declare that there is no conflict of interests regarding the publication of this paper.

\section{Acknowledgments}

The authors are thankful to the Research Council of Norway, Viken Skog BA, Treindustrien, the Wood Technology Research Fund at the Norwegian Institute of Wood Technology, Jotun AS, and Kebony ASA for the financial support and to the Norwegian University of Life Sciences (UMB), the Norwegian Forest and Landscape Institute, and the Norwegian Institute of Wood Technology for research cooperation. Additionally, the authors would like to acknowledge valuable comments from Dr. Per Jostein Hovde from NTNU and Dr. Lone Ross Gobakken from the Norwegian Forest and Landscape Institute at Ås, Norway.

\section{References}

[1] N. Strong, J. Webber, and R. Eaton, "Factors affecting the fungal colonization of pine lumber," Forest Pathology, vol. 35, no. 3, pp. 195-203, 2005.

[2] D.-Q. Yang, M. Gignac, and M.-C. Bisson, "Sawmill evaluation of a bioprotectant against moulds, stain, and decay on green lumber," Forest Products Journal, vol. 54, no. 9, pp. 63-68, 2004. 
[3] R. A. Eaton and M. D. C. Hale, Wood: Decay, Pests and Protection, Chapman \& Hill, London, UK, 1993.

[4] A. Schirp and M. P. Wolcott, "Influence of fungal decay and moisture absorption on mechanical properties of extruded wood-plastic composites," Wood and Fiber Science, vol. 37, no. 4, pp. 643-652, 2005.

[5] S. Bartnicki-García, "Glucans, walls, and morphogenesis: on the contributions of J. G. H. Wessels to the golden decades of fungal physiology and beyond," Fungal Genetics and Biology, vol. 27, no. 2-3, pp. 119-127, 1999.

[6] S. M. Bowman and S. J. Free, "The structure and synthesis of the fungal cell wall," BioEssays, vol. 28, no. 8, pp. 799-808, 2006.

[7] L. A. Derry, "Atmospheric science-fungi, weathering, and the emergence of animals," Science, vol. 311, no. 5766, pp. 1386-1387, 2006.

[8] P. Bednarek and A. Osbourn, "Plant-microbe interactions: chemical diversity in plant defense," Science, vol. 324, no. 5928, pp. 746-748, 2009.

[9] D. C. Eastwood, D. Floudas, M. Binder et al., "The plant cell wall-decomposing machinery underlies the functional diversity of forest fungi," Science, vol. 333, no. 6043, pp. 762-765, 2011.

[10] L. Tedersoo, M. Bahram, S. Põlme et al., "Global diversity and geography of soil fungi," Science, vol. 346, no. 6213, 2014.

[11] H. L. Barnett, "Fungi-an advanced treatise-fungal cell," Science, vol. 150, p. 1021, 1965.

[12] J. L. Marx, "Chitin synthesis inhibitors: effects on fungi?" Science, vol. 198, no. 4315, p. 354, 1977.

[13] D. S. Heckman, D. M. Geiser, B. R. Eidell, R. L. Stauffer, N. L. Kardos, and S. B. Hedges, "Molecular evidence for the early colonization of land by fungi and plants," Science, vol. 293, no. 5532, pp. 1129-1133, 2001.

[14] S. V. Diehl, M. L. Prewitt, and F. M. Shmulsky, "Use of fatty acid profiles to identify white-rot wood decay fungi," in Wood Deterioration and Preservation-Advances in Our Changing World, B. Goodell, D. D. Nicholas, and T. P. Schultz, Eds., p. 313, American Chemical Society, Washington, DC, USA, 2003.

[15] J. Šandula, G. Kogan, M. Kačuráková, and E. MacHová, "Microbial $(1 \rightarrow 3)-\beta$-D-glucans, their preparation, physicochemical characterization and immunomodulatory activity," Carbohydrate Polymers, vol. 38, no. 3, pp. 247-253, 1999.

[16] R. Schindler and B. Lendl, "Simultaneous determination of enzyme activities by FTIR-spectroscopy in an one-step assay," Analytica Chimica Acta, vol. 391, no. 1, pp. 19-28, 1999.

[17] B. P. Jelle, I. Myklebost, J. Holme, P. J. Hovde, and T. N. Nilsen, "Attenuated total reflectance (ATR) Fourier transform infrared (FTIR) radiation studies of wood rot decay and fungus growth on building materials," in Proceedings of the 11th DBMC International Conference on Durability of Building Materials and Components, p. 665, Istanbul, Turkey, May 2008.

[18] B. S. Gupta, B. P. Jelle, P. J. Hovde, and J. Holme, "Characterization of wood mould fungi by FTIR-a valuable step for prediction of initiation of decay," in Proceedings of the 12th DBMC International Conference on Durability of Building Materials and Components, Porto, Portugal, April 2011.

[19] R. Abu Ali, R. J. Murphy, and D. J. Dickinson, "Investigation of the extracellular mucilaginous materials produced by some wood decay fungi," Mycological Research, vol. 103, no. 11, pp. 1453-1461, 1999.

[20] S. Backa, J. Gierer, T. Reitberger, and T. Nilsson, "Hydroxyl radical activity in brown-rot fungi studied by a new chemiluminescence method," Holzforschung, vol. 46, no. 1, pp. 61-67, 1992.
[21] H. P. Wang, H.-C. Wang, and Y.-J. Huang, "Microscopic FTIR studies of lung cancer cells in pleural fluid," Science of the Total Environment, vol. 204, no. 3, pp. 283-287, 1997.

[22] E. Cabib, B. Bowers, A. Sburlati, and S. J. Silverman, "Fungal cell wall synthesis: the construction of a biological structure," Microbiological sciences, vol. 5, no. 12, pp. 370-375, 1988.

[23] M. D. Lenardon, R. K. Whitton, C. A. Munro, D. Marshall, and N. A. R. Gow, "Individual chitin synthase enzymes synthesize microfibrils of differing structure at specific locations in the Candida albicans cell wall," Molecular Microbiology, vol. 66, no. 5, pp. 1164-1173, 2007.

[24] A. Matusevičius, M. Ivaškiene, and V. Špakauskas, "Antifungal drugs. Part I. Fungal cell structure, function and susceptible targets for antifungal agents. Review," Veterinarija Ir Zootechnika, vol. 43 , no. 65 , pp. 3-13, 2008.

[25] A. Naumann, M. Navarro-González, S. Peddireddi, U. Kües, and A. Polle, "Fourier transform infrared microscopy and imaging: detection of fungi in wood," Fungal Genetics and Biology, vol. 42, no. 10, pp. 829-835, 2005.

[26] M. Novák, A. Synytsya, A. Veselá, G. K. Gomba, and J. Čopíková, "Structural investigation of glucan complexes isolated from Phellinus and Inonotus wood fungi," Chemicke Listy, vol. 104, no. 4, pp. 236-242, 2010.

[27] P. Pérez and J. C. Ribas, "Cell wall analysis," Methods, vol. 33, no. 3, pp. 245-251, 2004.

[28] S. B. Widjanarko, A. Nugroho, and T. Estiasih, "Functional interaction components of protein isolates and glucomannan in food bars by FTIR and SEM studies," African Journal of Food Science, vol. 5, p. 12, 2011.

[29] A. Barth and C. Zscherp, "What vibrations tell us about proteins," Quarterly Reviews of Biophysics, vol. 35, no. 4, pp. 369430, 2002.

[30] E. Marco-Urrea, E. Aranda, G. Caminal, and F. Guillén, "Induction of hydroxyl radical production in Trametes versicolor to degrade recalcitrant chlorinated hydrocarbons," Bioresource Technology, vol. 100, no. 23, pp. 5757-5762, 2009.

[31] C. R. Jordan, W. V. Dashek, and T. L. Highley, "Detection and quantification of oxalic acid from the brown-rot decay fungus, Postia placenta," Holzforschung, vol. 50, no. 4, pp. 312-318, 1996.

[32] B. Goodell, "Brown-rot fungal degradation of wood: our evolving view," Wood Deterioration and Preservation, vol. 845, pp. 97118,2003

[33] J. M. Legal, M. Manfait, and T. Theophanides, "Applications of FTIR spectroscopy in structural studies of cells and bacteria," Journal of Molecular Structure, vol. 242, pp. 397-407, 1991.

[34] J. A. Martín, A. Solla, S. Woodward, and L. Gil, "Fourier transform-infrared spectroscopy as a new method for evaluating host resistance in the Dutch elm disease complex," Tree Physiology, vol. 25, no. 10, pp. 1331-1338, 2005.

[35] J. A. Martin, A. Solla, S. Woodward, and L. Gil, "Detection of differential changes in lignin composition of elm xylem tissues inoculated with Ophiostoma novo-ulmi using Fourier transform-infrared spectroscopy," Forest Pathology, vol. 37, no. 3, pp. 187-191, 2007.

[36] J. A. Martin, A. Solla, M. A. Coimbra, and L. Gil, "Metabolic fingerprinting allows discrimination between Ulmus pumila and U. minor, and between U. minor clones of different susceptibility to Dutch elm disease," Forest Pathology, vol. 38, no. 4, pp. 244-256, 2008. 

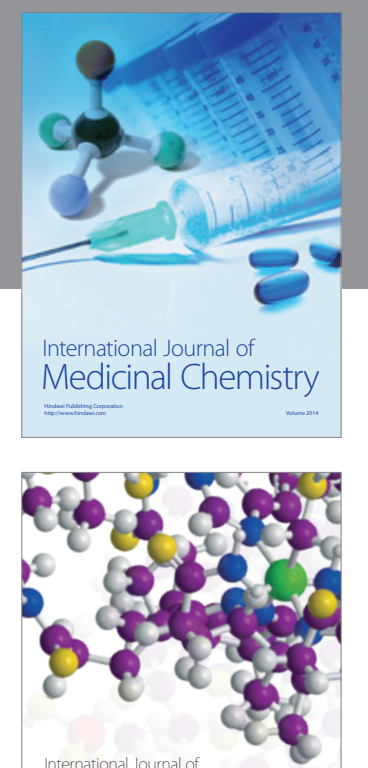

\section{Carbohydrate} Chemistry

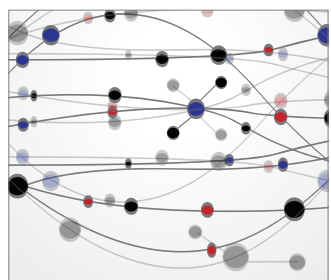

The Scientific World Journal



Submit your manuscripts at

http://www.hindawi.com

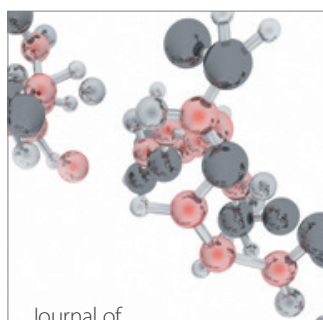

Analytical Methods

in Chemistry



Journal of

Applied Chemistry



Inorganic Chemistry
